\title{
Consumer behavior - people intolerant to gluten and gluten-free offer in the public catering sector
}

\author{
Daniela Šálková1*, Pavla Hošková \\ ${ }^{1}$ Department of Trade and Finance, FEM, Czech University of Life Sciences Prague, Kamýcká 129, 16521 Prague 6-Suchdol, Czech Republic, \\ ${ }^{2}$ Department of Statistics, FEM, Czech University of Life Sciences Prague, Kamýcká 129, 16521 Prague 6 - Suchdol, Czech Republic
}

\section{A B S T R A C T}

\begin{abstract}
Background: Following a lifelong gluten-free diet may be very difficult for the involved individuals, especially when visiting restaurants and other dining establishments. Aims: With respect to the growing popularity and public interest in the gluten-free diet and other specific food allergies, the objective was to determine what are the current consumer preferences of celiacs when eating out and what is their view on the relevant food offer in the public catering sector. The other objective was to examine the dependence of the selected traits important for the consumer behavior in the decision-making process when choosing dining facilities. Methods: We used a comparative research with a combination of quantitative and qualitative research in the Czech Republic. The contingency tables were used to evaluate the data obtained from the research. Results: We interviewed 603 celiac consumers. We demonstrated the positive correlation between the economic status and selection of dining facilities in the case of public catering, between the frequency of eating out in a restaurant and available discounts and special offers and the selection of the dining facility type, as well as other factors influencing the purchase of a particular food.
\end{abstract}

Keywords: Catering service; Celiac disease; Food safety; Gluten; Gluten free diet

\section{INTRODUCTION}

Adherence to a lifelong gluten-free diet, despite being the only effective protection against celiac disease, may be very difficult for the affected individuals. The growing availability of gluten-free foods and ingredients for meal preparation allows celiacs to modify their diet and get a relatively broad potential of home cooking. The social phobia of the affected patients should diminish with the increasing public awareness of gluten-related disorders (Aziz, 2014). Most consumers consider visiting restaurants, coffee shops and other dining facilities to be a completely normal part of their life. For a patient with a gluten-free diet, however, this can pose a very difficult situation. The simple act of choosing from a menu can become a difficult task, from the choice of the food itself so that it meets the conditions of safe food, to potential concerns about communication with the serving staff. When visiting a restaurant, some consumers may fear about deterioration of their health due to an accidental dietary mistake (Cureton, 2006). This may pose certain social constraints for celiac consumers and impair their lifestyle.
Currently, there are restaurants offering dishes that are naturally gluten-free. In some restaurants, the waiting staff and cooks are willing to prepare food from the menu, upon agreement with the customer, while modifying the ingredients to become gluten-free. Still, this is a potentially hazardous situation. Even if a restaurant is willing to modify a meal from its menu in order to meet the requirements of a celiac customer, or directly offers gluten-free food, there could be a problem. A problem, that may affect celiacs, who are very sensitive to gluten. In fact, cross-contamination may occur during the harvest, delivery, food storage or preparation of the finished food. This means that the gluten-free food may come into contact with foods containing e.g. wheat flour or with inadequately cleaned utensils and preparation surfaces, where gluten-containing food was previously cooked. This may occur, for example, with the roasting pan where the food was recently dusted with flour. This may happen if the cooks or chefs are poorly familiarized with the rules they should follow when preparing gluten-free food.

As demonstrated in research by Mcintosh et al. (2011), neither any declaration from the restaurant about sale of

\footnotetext{
*Corresponding author:

Daniela Šálková, Department of Trade and Finances, Faculty of Economics and Management, Czech University of Life Sciences, The Czech Republic. E-mail: salkova@pef.czu.cz
} 
gluten-free food nor any recommendations of the staff, use of the crossed-out ear symbol and food a la carte, do not provide a guarantee for the celiac consumer that the prepared food has been really prepared according to the principles of gluten-free diet. Generally, it can be said that eating out at a restaurant can often pose a significant health risk (Bryan, 2012). Patients, who are forced to follow a gluten free diet, are justifiably cautious, if they have to consume food prepared outside the home. Training of chefs and waiting staff about the principles for gluten-free diet is one of the ways to mitigate the social constraints of celiacs (Karajeh et al., 2005).

In the Czech Republic, only very few public catering establishments can be found where meals are prepared according to the rules of a gluten-free diet. In restaurants, the offer of gluten-free foods has been gradually improving. The situation is worse in the case of, for example, school canteens, where only a very small percentage of the food offer generally is free of serious food allergens. Virtually no fast food offers gluten-free food or food uncontaminated with gluten-containing products (Salkova and Regnerova, 2014). Special caution is required even in a coffee shop, as even coffee may contain some hidden gluten. What are the current consumer preferences of celiacs when eating out and what is their view on the relevant food offer in the public catering sector?

\section{MATERIALS AND METHODS}

Consumer behaviour, with respect to people with gluten intolerance and availability of food offer following the principles of gluten-free diet in the catering sector, was studied by means of a comparative research combined with quantitative and qualitative research. The data was collected from February 2013 until June 2014. A total of 603 people with gluten-free diet were interviewed, including people who were either diagnosed with celiac disease or just adhere to the gluten-free diet.

The data obtained from the questionnaire survey mostly have the character of the qualitative traits. If the data set is sorted according to the values (or variations) of two categorical variables, the result is known as a contingency table. This table is the starting point for studying the relationships between these variables. If the data classified in the contingency table originates from a sample acquired by random selection from the basic population, the possibility to generalize the results obtained from a sample of the entire population should be verified. Test procedures are used for this purpose, which verify the statistical significance of the relationship between the selected categorical variables, i.e. the existence of dependencies. The primary test used to detect the interdependence is the chi-square test of independence. The hypothesis is tested that the observed variables are independent. It is assumed that if two traits are independent, the frequency distribution in the contingency table is proportional to the row and column marginal frequencies. The test criterion is generally defined as:

$$
\chi^{2}=\sum_{i=1}^{r} \sum_{j=1}^{s} \frac{\left(n_{i j}-o_{i j}\right)^{2}}{o_{i j}},
$$

where $\mathrm{n}$ - is sample size

$\mathrm{n}_{\mathrm{ij}-}$ empirical frequency,

$\mathrm{O}_{\mathrm{ij}-}$ the expected (theoretical) frequency,

$\mathrm{i}=1,2 \ldots, \mathrm{r}$, where $\mathrm{r}$ is the number of single trait permutations,

$\mathrm{j}=1,2 \ldots, \mathrm{s}$, where $\mathrm{s}$ is the number of second trait permutations.

$\chi^{2}$ statistics expresses the concordance between the frequencies obtained by sorting data in the contingency table $\left(\mathrm{n}_{\mathrm{ij}}\right)$ and the frequency expected in the case of independence variables $\left(\mathrm{O}_{\mathrm{ij}}\right)$ (Pecakova, 2011).

The theoretical frequency is estimated based on the corresponding peripheral (marginal) frequencies and sample sizes. The $\chi^{2}$ statistics, when the null hypothesis is valid, has the chi-square distribution with $(r-1)(s-1)$ degrees of freedom. The hypothesis of independence between the traits will be rejected at $\alpha$ significance level, if the test criterion value is greater than $100(1-\alpha) \%$ quantile of the chi-square distribution, or if the minimum significance level for rejection of the hypothesis tested (p-value) is less than $\alpha$ (Mark et al., 2013).

If the hypothesis of independence of traits is rejected at the selected level of significance, the test demonstrates dependence between the traits. Further evaluation of the contingency table should include identification of the degree of dependence intensity between the traits. The aim of measuring the intensity of dependence is to get an idea about the extent to which the behavior of one variable can be used to deduce the behavior of the second variable (Pecakova, 2011). The strength (intensity) of dependence of two categorical variables can be evaluated using Pearsonss contingency coefficient

$$
C=\sqrt{\frac{\chi^{2}}{n+\chi^{2}}},
$$

which in the case of independence is zero. The value of this coefficient is influenced by the population size and dimensions of the contingency table. With the increasing

Emir. J. Food Agric • Vol $28 \bullet$ Issue 4 • 2016 
number of rows and columns in the table, the maximum coefficient gets closer to one, but its interpretation is impaired by the dependence on the contingency table size (Mark et al., 2013).

The degree of dependence can also be evaluated using the Cramérs contingency coefficient which is zero in the case of independence. In other cases, it takes values from the interval $<0,1>$.

$$
V=\sqrt{\frac{\chi^{2}}{n(b-1)}}, \text { where } \mathrm{h}=\min .(\mathrm{r}, \mathrm{s}) \text {. }
$$

\section{RESULTS AND DISCUSSION}

Celiac disease is a lifelong, multi-systemic, immunemediated disease characterized by sustained intolerance to gluten. It is an inflammatory disease of the small intestine, which occurs in children and adults. It is caused by intolerance to gluten, a protein complex contained in the superficial part of the cereal grains. We can talk about malabsorption of the breakdown products resulting from digestion of proteins, fats and sugars, water, minerals, vitamins and other substances. The disorder is also associated with a marked increase in mucus production and impaired mobility of the small intestinal wall (Celostni medicina, 2014).

"Gluten" - is usually understood as the fraction of hydrated prolamin (gliadin) and glutein wheat proteins, which are located together with starch in the endosperm of some seeds of cereals. The disease is caused by fractions of hydrated prolamin (gliadin) and glutein wheat proteins or glutein fractions of barley proteins (hordein) and rye (secalins). Changes in the lining of the small intestine caused by celiac disease impair the absorption of nutrients from food, which may lead to serious consequences in the patient's health. "In addition to the gastrointestinal system, celiac disease can also involve other body systems and cause conditions including short stature, osteoporosis, and irondeficiency anaemia“" (Moreno, 2014).

Epidemiological studies carried out during the last decade have revealed the fact that coeliac disease is one of the world's most common life-long diseases (Fasano et al., 2008). At present, celiac disease can be effectively managed only through adherence to a gluten-free diet, despite the fact that multiple drugs have been tested and examined to supplement or even fully replace the gluten-free diet (Anderson, 2008). This diet is very restrictive. This strict dietary restriction may be associated with elevated levels of psychological distress, depression, anxiety and social phobia (Rose and Howard, 2014).
With respect to the growing popularity and public interest in the gluten-free diet and other specific food allergies, the objective was to determine what are the current consumer preferences of celiacs when eating out and what is their view on the relevant food offer in the public catering sector. At the same time, the other objective was to examine the dependence of the selected traits important for the consumer behavior in the decision-making process when choosing dining facilities.

In real life, however, most celiacs use the possibility of eating out very rarely (Fig. 1). Only one out of four consumers has reported eating in restaurants every day or every other day. There are multiple reasons, such as limited and insufficient offer in the dining facilities, small staff awareness, concerns about the deterioration of health, for example, due to secondary contamination of food with gluten proteins during the food preparation, or high prices. Approximately one out of five consumers use dining facilities in the public catering sector at least once a week $(23 \%)$ and more than half of them $(51 \%)$ less than once a week or not at all.

The investigation and subsequent testing demonstrated a statistically significant dependence between gender and type of dining facility most frequently used by celiacs to eat out (Table 1). Most consumers prefer restaurants with service (55\%), while the second most visited type of eating facilities are school $(12 \%)$ or plant $(10 \%)$ canteens. Dining facilities least frequently visited for gluten-free diet are fast food restaurants, which essentially serve no gluten-free food at all, you can only combine naturally gluten-free food, which is used only by $10 \%$ of celiacs for eating.

In addition to the correlation between gender and type of dining facility, $\chi^{2}$ - test was used to confirm the correlation between the age of consumers and their education, which also helps decide about the selection of a particular restaurant facility.

A statistically significant relationship $(\mathrm{p}=0.001)$ was also confirmed in the case of the factors that influence the choice of dining facilities and the age of consumers, their education and economic status (Table 2). These are the following factors: the freshness and quality of food, price level, choice of gluten-free foods, friendly and helpful staff, operating hours. Wide choice of food for gluten-free diet (63\%) and freshness and quality of food $(49 \%)$, and also the price level $(27 \%)$ have been identified

Table 1: Dependence between gender and type of dining facility

\begin{tabular}{lccc}
\hline Statistic & DF & Value & Prob \\
\hline Chi-square & 60 & 80.8202 & 0.0379 \\
Contingency coefficient & & 0.3438 & \\
Cramer's V & & 0.2114 & \\
\hline
\end{tabular}


as crucial determinants that have the greatest influence on the selection of dining facility, which confirms a great importance of health for celiacs and the potential risk of health impairment which in this case has a direct relationship that cannot be underestimated.

Important aspects when choosing a particular food from the available choice of an eating facility, according to which celiacs most commonly make buying decisions, are the health aspects and their impacts on the body and previous good experience (Fig. 2).

Significant dependence was confirmed based on the $\chi^{2}$ test even in the case of gender and economic status in relation to the assessment criteria to evaluate the quality of the purchased gluten-free foods (Table 3). The decisive factor in this case is the composition of the food (61\%) and good personal experience $(57 \%)$ or recommendation of another person $(25 \%)$.

A statistically significant correlation was also demonstrated (Table 4) between choosing the type of a dining facility and eating, as the most common site of visits and factors influencing the choice of the dining facility along with the decisive criteria for the purchase of specific gluten-free products.

The vast majority of celiacs consider their economic costs for adherence to the principles of gluten-free diet, i.e. the price of gluten-free foods in relation to the total expenditure on food to be high (79\%). This shows, among other things, the financial burden of this disease. Since

Table 2: Relationship between the economic status and decision regarding selection of a dining facility

\begin{tabular}{lccc}
\hline Statistic & DF & Value & Prob \\
\hline Chi-square & 129 & 200.8425 & $<0.0001$ \\
Contingency coefficient & & 0.4999 & \\
Cramer's V & & 0.3332 & \\
\hline
\end{tabular}

Table 3: Correlation between the economic status and decision-making regarding the facility

\begin{tabular}{lccc}
\hline Statistic & DF & Value & Prob \\
\hline Chi-square & 15 & 31.2740 & 0.0081 \\
Contingency coefficient & & 0.2221 & \\
Cramer's V & & 0.2277 & \\
\hline
\end{tabular}

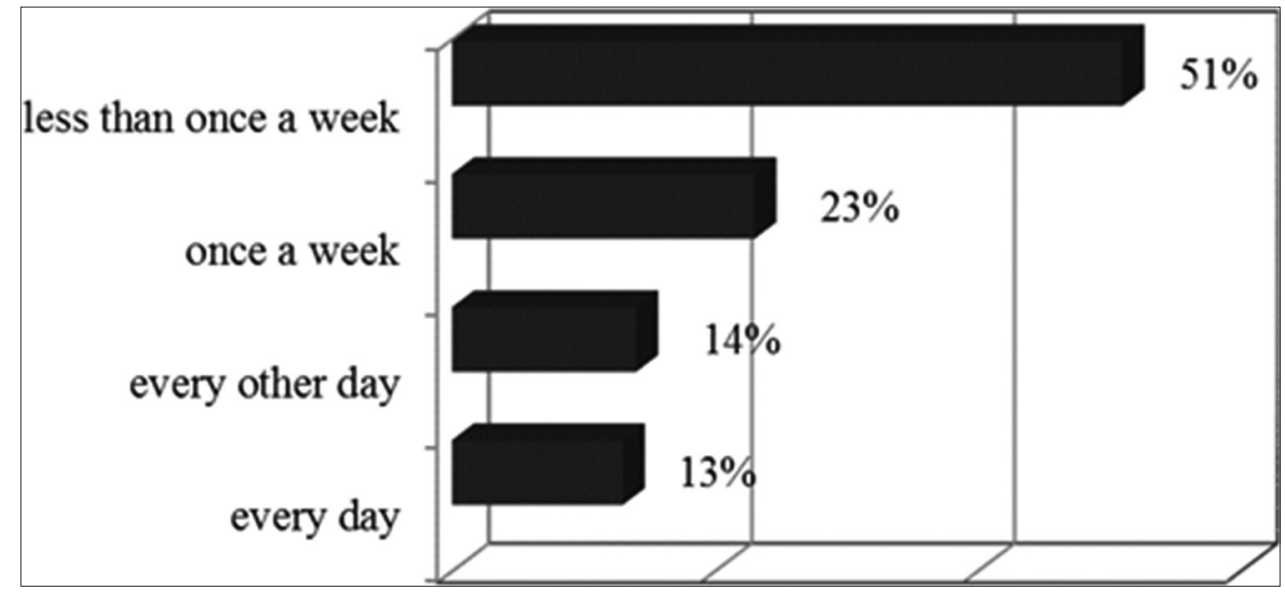

Fig 1. The frequency of eating out among celiacs

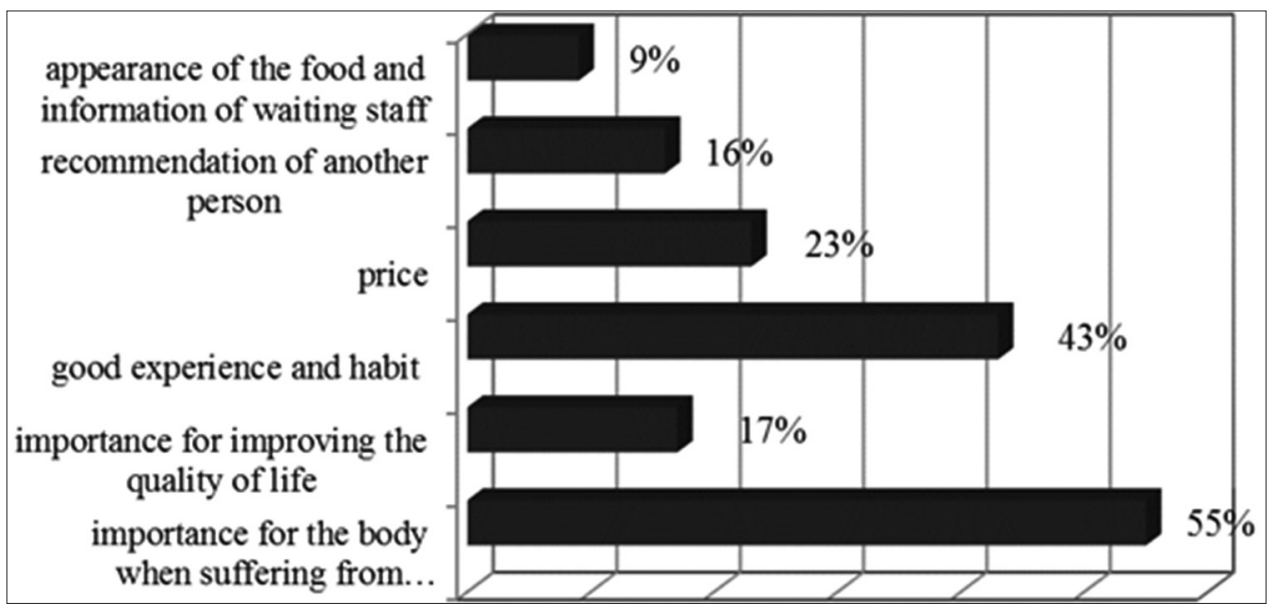

Fig 2. Relevant factors for food choice 
the exclusion of gluten-containing foods is basically the only way to effectively reduce the effects of this disease, the price of gluten-free foods and ready gluten-free meals can significantly limit the possibilities for eating out among people with celiac disease. This is evidenced by the findings that occasional discounts and special offers are very important for $28 \%$ of celiacs and partially important for $49 \%$ of celiacs when buying gluten-free foods. The investigation and subsequent verification by specific tests showed a direct correlation between the frequency of eating out in dining facilities and significance of the discounts offered (Table 5), along with the correlation between choosing the type of dining facility and special price offers (Table 6).

For the majority of celiac consumers included in the survey, the current choice of gluten-free foods and meals in the public catering sector is totally insufficient $(78 \%)$. This suggests a low choice of meals suitable for adherence to this specific diet. In the same way, most of the consumers welcomed the expansion of the gluten-free offer, including establishment of new facilities intended exclusively for this type of food, that can optionally be combined with other offers for food allergies. New eating facilities with choice of gluten-free foods and meals would be welcomed by $93 \%$ of celiacs.

\section{CONCLUSIONS}

In general, the situation in the area of food products and other types of meals for those with specific food allergies, as well as the awareness of the general public, have been

\begin{tabular}{|c|c|c|c|}
\hline Statistic & DF & Value & Prob \\
\hline Chi-square & 1140 & 2230.7934 & $<0.0001$ \\
\hline Contingency coefficient & & 0.8872 & \\
\hline Cramer's V & & 0.4301 & \\
\hline
\end{tabular}

Table 5: Correlation between the frequency of eating out in restaurants and importance of discounts offered

\begin{tabular}{lccc}
\hline Statistic & DF & Value & Prob \\
\hline Chi-square & 9 & 30.1940 & 0.0004 \\
Contingency coefficient & & 0.2184 & \\
Cramer's V & & 0.1292 & \\
\hline
\end{tabular}

Table 6: Correlation between the type of dining facility and importance of the discounts offered

\begin{tabular}{lccc}
\hline Statistic & DF & Value & Prob \\
\hline Chi-square & 60 & 95.8430 & 0.0023 \\
Contingency coefficient & & 0.3703 & \\
Cramer's V & & 0.2302 & \\
\hline
\end{tabular}

gradually improving. Even so, there is still plenty of room in the Czech Republic, especially for operators of restaurants and other dining facilities, to considerably improve the gluten-free offer. Customers would often welcome, in all types of dining facilities, extension of the choice of glutenfree meals, even at a higher price. No less important feature is the improved awareness of the serving staff and persons preparing the dishes so that they can respond adequately and provide suitable food at the request of the customer.

Big differences can be found among the eating possibilities for people with gluten-free diet. The size and location of the facility plays an important role here. In general, the smaller the place in which the unit is operating, the smaller the volume of the offered range of foods for gluten-free diet.

In the case of restaurants with service it would be appropriate if the gluten-free dishes were labelled in the menu with symbol of crossed out spike, or if the meal was annotated that it is possible to be prepared in the glutenfree version. One of the recommendations for fast food is to include in the menu the gluten-free flour bread and improve the familiarity of operating personnel with catering to celiacs. For Canteen (school canteens and cafeterias) it would be useful mainly to extend offered assortment of gluten-free foods, in a number of establishments there are no gluten-free dishes offered at all. The next step, and subject to further investigation might be in this case creating a map of restaurants with service, school cafeterias and fast-food, where the customer with the need for glutenfree diets would eat without problems on the territory of a city, district or region.

With their growing number, celiacs (thousands of people are involved, and the number of food allergies will further rise) certainly represent a considerable group of consumers, which has its own specific needs and requirements that cannot be ignored in the food offer.

\section{ACKNOWLEDGMENT}

The information presented in this paper resulted from the solution of a project of IGA No. 20141033, Faculty of Economics and Management "Availability of dining for celiacs (with a gluten-free diet) in Hospitality Establishments in the CR and Their social responsibility towards the Monitored group of consumers".

\section{Author Contributions}

S. D. made a major contribution in paper writing and overall planning of the study, supervised the research and reviewed the paper. P.H. processed statistical data analysis. 


\section{REFERENCES}

Anderson, R. P. 2008. Coeliac disease: Current approach and future prospects. Int. Med. J. 38(10): 790-799.

Aziz, I., M. A. Karajeh, J. Zilkha, E. Tubman, C. Fowles and D. S. Sanders. 2014. Change in awareness of gluten-related disorders among chefs and the general public in the UK: A 10-year followup study. Eur. J. Gastroenterol. Hepatol. 2014;26:1128-33. Article in Press.

Bryan, A. 2012. The Gluten Free Guide to Fast Food Restaurants. Studio, Diamond Head, p 76.

Cureton, P. 2006. Gluten-free dining out: Is it safe? Pract. Gastroenterol. 30(11), 61-68.

Fasano, A., R. Troncone and D. Branski. 2008. Frontiers in Celiac Disease. Karger, Basel, p. 222.

Karajeh, M. A., D. P. Hurlstone, T. M. Patel and D. S. Sanders. 2005. Chefs' knowledge of coeliac disease (Compared to the Public): A questionnaire survey from the United Kingdom. Clin. Nutr. 24(2): 206-210.

Marek, L., I. Pecakova, M. Vrabec, T. Löster and A. Čabla. 2013.
Statistics in Examples. 1st ed. Professional Publishing, Prague, p. 403.

Mcintosh, J., A. Flanagan, N. Madden, M. Mulcahy, L. Dargan, M. Walker and D. T. Burns. 2011. Awareness of coeliac disease and the gluten status of 'gluten-free' food obtained on request in catering outlets in Ireland. Int. J. Food Sci. Technol. 46(8): 1569-1574.

Moreno, M. 2014. Celiac disease in children and adolescents. Jama Pediatr. 168: 295-295.

Pecakova, I. 2011. Statistics on Field Surveys. 2nd ed. Professional Publishing, Prague, p. 236.

Rose, C. and R. Howard. 2014. Living with coeliac disease: A grounded theory study. J. Hum. Nutr. Diet. 27(1): 30-40.

Šálková, D. and M. Regnerova. 2014. Gluten-free dining options in the Czech Republic. Proceedings of the 23th International Scientific Conference Agrarian perspectives Xxiii The Community-led Rural Development, Pp. 345-352.

Celiakie. (Intolerance Lepku). Available from: http://www. celostnimedicina.cz/celiakie-a-potraviny-bez-lepku. htm\#ixzz3QgqschMC. [Last cited on 2014 Dec 01]. 